\title{
Does response shift impact interpretation of change even among scales developed using item response theory?
}

\author{
Carolyn E. Schwartz ${ }^{1,2^{*}}$ D, Brian D. Stucky ${ }^{3}$, Wesley Michael ${ }^{4}$ and Bruce D. Rapkin ${ }^{5}$
}

\begin{abstract}
Background: Response-shift effects impact the interpretation of change in quality-of-life (QOL) measures developed with classical test theory (CTT) methods. This study evaluated the impact of response shift on measures developed using Item Response Theory (IRT), as compared to CTT.

Methods: Chronically ill patients and caregivers $(n=1481)$ participated in a web-based survey at baseline and 17 months later. Patients completed the IRT-based PROMIS-10; NeuroQOL Applied Cognition, Positive Affect \& WellBeing short-forms; and the CTT-based Ryff Environmental Mastery subscale. Response-shift effects were evaluated using regression residual modeling and the QOL Appraisal Profile-v2. The sample was divided into positive and negative catalyst groups on the basis of marital, work, job-status, and comorbidity change. Regression models predicted residualized QOL change scores as a function of catalysts and appraisal changes.
\end{abstract}

Results: In this sample 859 (58\%) reported a catalyst. No catalyst was associated with change in scales developed using IRT, but positive work change was associated with the CTT-based measure. Catalyst variables were associated with changes in appraisal, which in turn were related to all outcomes, particularly for global mental health after a positive work-change.

Conclusions: Appraisal processes are relevant to interpreting IRT measures, particularly for global mental health in the face of life changes.

Keywords: Item response theory, Classical test theory, Residual modeling, Response shift, Appraisal, Life events

\section{Introduction}

Research on a broad range of patient populations has suggested that response-shift effects can attenuate estimates of treatment benefit [1-8] and can explain paradoxical findings of improved quality of life (QOL) despite objectively poor functional status [9-16]. Response-shift theory $[17,18]$ predicts that when people experience a healthstate change or catalyst, they may change their internal standards, values, or conceptualization of QOL (Fig. 1). These response-shift effects are influenced by stable characteristics of the individual (antecedents); as well as cognitive, behavioral, or affective processes (mechanisms). Appraisal processes are the basis for response shift:

\footnotetext{
* Correspondence: carolyn.schwartz@deltaquest.org

${ }^{1}$ DeltaQuest Foundation, Inc., 31 Mitchell Road, Concord, MA 01742, USA

${ }^{2}$ Departments of Medicine and Orthopaedic Surgery, Tufts University Medical

School, Boston, MA, USA

Full list of author information is available at the end of the article
}

Response shift is inferred when appraisal changes explain the discrepancy between expected and observed QOL, given the catalysts experienced [18]. Appraisal can directly influence QOL change (direct response shift) and can moderate the impact of the catalyst (moderated response shift) on QOL change.

Response shift research using the direct assessment of appraisal $[19,20]$ focuses on individual-level change in how respondents think about QOL and has revealed important differences in health outcomes and resilience over time [21-26]. This approach enables a descriptive understanding of adaptation processes, and can point to useful directions for clinical intervention. Recent developments of practical measures of appraisal processes allow for individual-level analysis that characterizes the underlying cognitive processes connoted by responseshift effects $[19,20]$. 


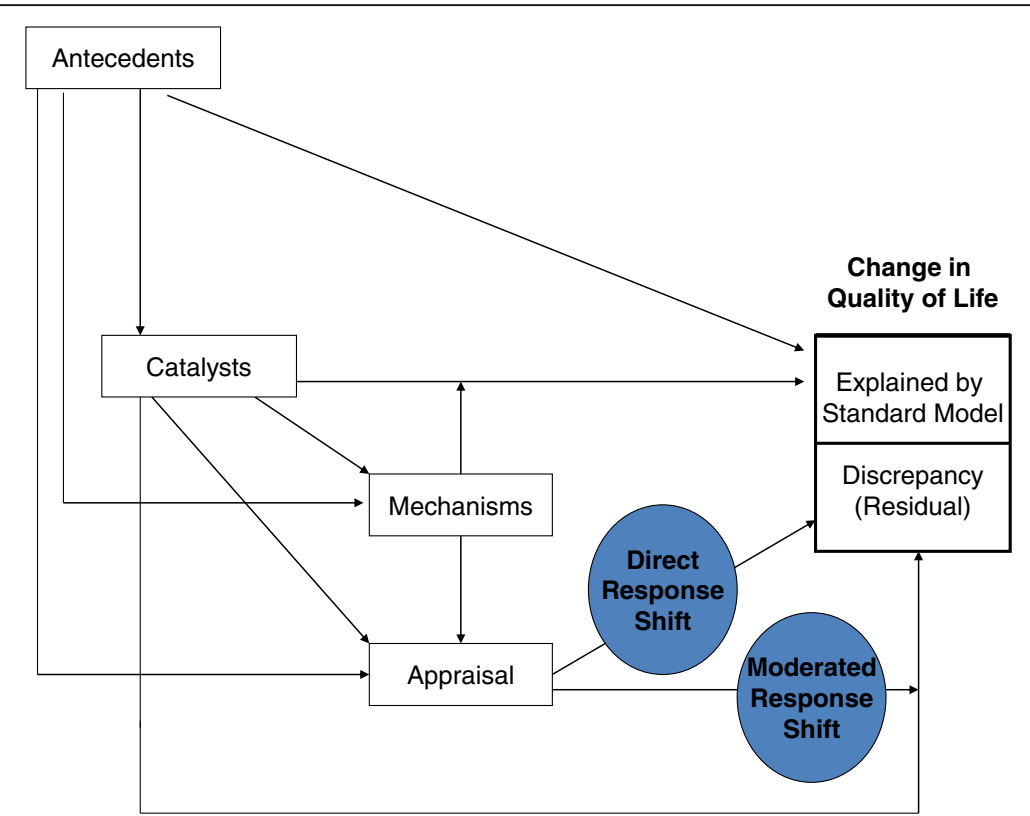

Fig. 1 The Rapkin and Schwartz theoretical model. This model tests for response-shift effects by predicting residualized QOL change. Antecedents are adjusted as covariates in the "standard QOL model", and the unexplained variance (residuals) is modeled as a function of catalysts and appraisal processes. Main effects of appraisal reflect direct response shift, and catalyst-by-appraisal interaction effects reflect moderated response shift

Many researchers familiar with methods of response shift detection based on lack of measurement invariance over time $[27,28]$ might reasonably assume that measures developed using item-response theory (IRT) [29] would be less subject to response shift. The logic is that IRT single-domain scales are designed to be unidimensional and, based on the probabilistic nature of the models, would have similar item characteristics across samples. Although IRT single-domain scales have generally been developed using cross-sectional data only, it would be reasonable to assume that the psychometric characteristics of IRT-based scales should be stable over time. They would thus be less subject to response shift effects as detected by measurement-invariance methods (e.g., Structural Equation Modeling). The motivation for this paper relates to differences in the strictness and rigor by which items are selected using IRT versus CTT. The IRT criteria for selecting items emphasize unidimensionality and are more rigorous and stricter than is the case with CTT. Those criteria ought to have the effect of being conceptually more linked to one another so may be reducing construct representation for the sake of internal consistency. The methods for evaluating differential item functioning (DIF) over time further enable selecting items whose characteristics are similar across sample or time, thereby reducing the likelihood of factorial variance and with it the likelihood of detecting certain types of response shift. Indeed, to the extent that items demonstrate DIF, they would also be more subject to appraisal differences and therefore to response-shift effects. Further, DIF methods may not be sufficient to detect response shift, not only because they focus on differences in item response in cross-sectional data due to stable characteristics of the individual (e.g., demographics), but also because response shift is by definition a longitudinal phenomenon (i.e., adaptation effects over time). Nonetheless, even if items do not demonstrate DIF, they may still be subject to appraisal differences and response-shift effects because these are part of adapting to change. Thus, even with the most measurement-invariant measures, these hallmarks of the human condition would be expected.

Thus, despite lack of evidence for response shift using measurement-invariance methods, individuals' understanding or experience of the latent trait can still change. Appraisal necessarily always occurs whenever individuals rate their QOL (i.e., they are thinking about something relevant to the questions they are answering). Individuals need not appraise QOL in the same way at different times of measurement even when item or scale characteristics remain stable (i.e., same overall factor structure, same factor loadings, same inter-item correlations, etc.). In fact, as many studies observing homeostasis of QOL scores across the course of illness suggest, people actually maintain a QOL set point across changing health status or exposure to catalysts by changing their appraisal [21-23, 30, 31]. 
This study investigates whether there are differences in sensitivity to response-shift effects among measures developed in different ways. We propose the distinction shown in Fig. 2: that there is a continuum of measurement sensitivity to response-shift effects, with the least sensitive generally being measures developed using IRT methods with the intention of developing a specific and unidimensional measure of a construct that would maximize internal consistency reliability (IRT single-domain measures). Measures hypothesized to be most sensitive to response-shift effects (CTTbased measures) would, on the one hand, be developed with a focus on alpha reliability and construct validity that follow logical arguments. Such measures would, however, have relatively fewer quantitative metrics. In fact, CCT-based measures do not have the benefit of model-fit statistics and item-function curves that IRT does. In between these two extremes on the continuum are measures that use IRT methods for calibration and item selection but which seek to be general tools for measuring QOL (i.e., maximizing band width) rather than measures of unidimensional constructs of domains (IRT multiple-domain measures). The analysis presented here will examine the extent to which IRT-unidimenstional measures demonstrate response shift in terms of responsiveness to catalysts, as well as their association with changes in appraisal. We hypothesize that compared to CTTbased and IRT multiple-domain measures, IRT singledomain measures will be less responsive to catalysts but similar in how much appraisal explains variance in change scores over time.

\section{Methods \\ Sample}

This secondary analysis utilized data collected from Rare Patient Voice, LLC and WhatNext panels, with a heterogeneous grouping of chronic health conditions (see www.rarepatientvoice.com). Eligible participants were patients with a chronic medical condition or their caregivers of age 18 years or older, and able to complete an online questionnaire.

\section{Procedure and design}

A web-based survey was administered twice (baseline, follow-up) using the Health Insurance Portability and Accountability Act (HIPAA)-compliant, secure SurveyGizmo engine (www.surveygizmo.com). (See [32] for full description of methods.) The study was reviewed and approved by the New England Review Board (NEIRB\#15-254), and all participants provided informed consent.

\section{Measures}

QOL was assessed using the following patient-reported outcomes (PROs): The IRT single-domain PROs included the NeuroQOL Applied Cognition General Concerns and Executive Function short-forms [33]; and the NeuroQOL Positive Affect \& Well-Being [33]. The IRT multiple-domain PRO included the Patient-Reported Outcome Measurement Information System (PROMIS)10 , yielding scores for global physical and global mental health [34]. Items were selected based on calibrations from large item banks for core domains of general health [34]. The CTT-based PRO was the 7-item Environmental Mastery subscale of the Ryff Psychological Well-

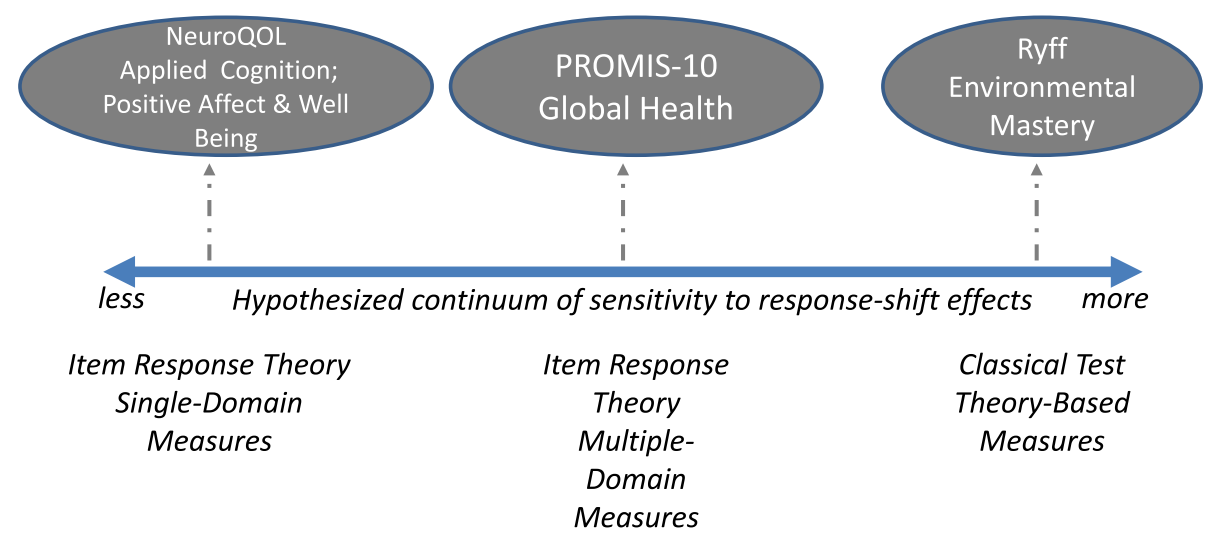

Fig. 2 Hypothesized Continuum of Sensitivity to Response-Shift Effects. We posit that there is a continuum of measurement sensitivity to response-shift effects, with the least sensitive being measures developed using IRT methods with the intention of developing a specific and unidimensional measure of a construct (IRT single-domain measures). Measures hypothesized to be most sensitive to response-shift effects would be developed with a focus on alpha reliability and construct validity that follow logical arguments but have relatively fewer quantitative metrics of model fit and item function than IRT (CTT-based measures). In between these two extremes are measures that use IRT methods for calibration and item selection but which seek to be general tools for measuring QOL rather than measures of unidimensional constructs of domains (IRT multiple-domain measures). 
Being measure [35]. The NeuroQOL and PROMIS-10 scores were computed using the raw score to $\mathrm{T}$-score conversion tables, resulting in a standardized $\mathrm{T}$-score metric $($ mean $=50, \mathrm{SD}=10)$ [33, 34]. The Ryff items are re-coded if negatively worded and summed to create a sum score [36]. Higher scores reflect better QOL on all measures.

Cognitive appraisal processes underlying responses to the patient-reported outcomes were assessed using the QOL Appraisal Profile - v2 [19]. This 85-item measure yields 12 orthogonal second-order component scores: Wellness Focus, Health Worries, Recent Challenges, Spiritual Focus, Relationship Focus, Maintain Roles, Independence, Reduce Responsibilities, Pursue Dreams, Anticipating Decline, Worry Free, and Lightness of Being. (See Additional file 1: Table S1 for details.) The interpretation of composite scores is a greater emphasis on the appraisal processes included in the component. In the case of negative versus positive loadings within a component, the interpretation would be one either attended to this pole (positive items) or tended to the opposite pole (negative items).

Demographic characteristics included year of birth, gender, ethnicity, race, cohabitation/marital status, with whom the person lives, employment status, annual household income categories, difficulty paying bills [37], and number of comorbidities, as measured by the SelfAdministered Comorbidity Questionnaire [38]. Occupational complexity was assessed using questions querying the job that was closest to the respondent's current or past occupation, which were then scored for complexity using the O*NET system. This comprehensive jobclassification system from the National Center for O*NET Development provides in-depth classification of job complexity, with higher scores reflecting more training and skills required to perform that occupation [39].

We created catalyst variables reflecting significant life events since the baseline data collection. Positive and negative changes in four domains were created: marital, work, job-status, and comorbidity-burden. Positive marital change comprised going from being single to cohabiting or married, whereas negative marital change comprised going from single or married to separated, divorced or widowed. Positive work change comprised going from employed to retired; unemployed to employed or disabled; retired or disabled to employed. In contrast, negative work change comprised going from employed to unemployed or disabled. Positive job-status change comprised getting a promotion (i.e., increase in job complexity) over follow-up, whereas negative job-status change comprised getting demoted (i.e., decrease in job complexity). Comorbidity-burden change comprised reporting new comorbidities over follow-up. The positive- and negative-life event groups were kept distinct by domain in subsequent analyses.

\section{Statistical analysis}

This analysis utilized the Rapkin and Schwartz' regression residual modeling approach $[18,40]$ to investigate response-shift effects. This application of standard regression modeling refers to the specific sets of variables included in the first "standard" model, and the responseshift interpretation when the residual can be explained by change in appraisal. Building on a precedent for using residual modeling to study epiphenomena [41], we computed "standard model" regressions separately for the five PRO change scores (Global Physical Health, Global Mental Health, Applied Cognition, Well-Being, Environmental Mastery). These models adjust for the sociodemographic/medical characteristics generally considered relevant to QOL (antecedents in Fig. 1). This "standard" model adjusted for age, age at diagnosis, gender, education, ethnicity, income, received help to complete survey, employment status, marital status, and baseline number of comorbidities. The model residuals were saved, and subsequent models used these residualized change scores as dependent variables. This residual-modeling approach highlights the effect of change, controlling for baseline values.

To assess selection biases, t-tests or chi-squared analyses compared demographic characteristics in the attrition and analytic samples. To reduce the number of variables included in the subsequent multivariable analyses, analysis of variance (ANOVA) was used to compare each appraisal score as well as the raw and residualized PRO change scores for the catalyst groups. Contrast variables were created for Marital, Work, and O*NET change such that a "-1" reflected negative change; "0" reflected no change; and " +1 " reflected a positive change. These dummy variables are coded to create contrasts for each concept measured so that the valence of the change is included in the dummy variable being analyzed. For comorbidity-burden change, a " 1 " reflected an increase and a score of "0" reflected no change.

The independent variables of the residualized-change analyses were catalyst groups, relevant appraisal domain identified by earlier ANOVAs, and their interaction if main effects were significant.. This paper is an exploratory analysis of a novel hypothesis. Accordingly, we have relaxed the Type I error rate to be 0.10 for deciding which variables to test in final models. Further, we have considered the results in light of what one would expect to find by chance (i.e., with a Type I error rate, one would expect to find $10 \%$ of comparisons to be "significant" by chance). Finally, we provide effect-size statistics for the above comparisons with conditional formatting and /or tabular footnotes to indicate effect-size magnitude as per Cohen $([42,43]$. Data analyses were implemented using Stata 15 [44]. 


\section{Results \\ Sample}

The study's analytic sample included 1212 patients, 227 caregivers, and 42 patient-caregivers. Mean follow-up was 16.7 months $(\mathrm{SD}=1.7$; range: $13.5-25.7)$. Table 1 provides the sociodemographic characteristics and reported comorbidities of this heterogeneous sample.

Selection-bias analyses revealed that the participants retained in the study were slightly older, less likely to be caregivers, more likely to have arthritis, and less likely to have an ulcer or stomach disease (Table 1). They were more likely to be non-Hispanic, White, and more educated; and to be/have been engaged in occupation requiring extensive preparation.

Table 2 shows the catalyst groups created for positive and negative significant life events. More people reported positive changes than negative changes on marital status and work change (ratio of 1.5 and 2.3, respectively). In contrast, job-status changes were equally divided among promotion and demotion. Overall, the life-changes reflected $3-35 \%$ of the sample, with the most prevalent being job-status change and the least prevalent being comorbidity-burden change.

The largest PRO changes were found in the PROMIS Global Mental Health, PROMIS Global Physical Health, and NeuroQOL Applied Cognition General Concerns $(\mathrm{t}=-12.95,-1.92$, and 1.69 , respectively; $p<0.0001$, 0.03 , and 0.05 , respectively; Table 3 ), all suggesting deterioration on the PRO over time. The other PROs showed non-significant change over time. The appraisal change scores were also generally small, with the largest mean changes found in Health Worries and Recent Challenges. Of note, the standard deviation of the mean change scores were relatively large, as were the ranges, suggesting substantial change distributions across the variables of interest in the study sample.

Different appraisal-change scores were relevant to the catalyst groups (Table 4). People who married or started an intimate relationship placed a greater emphasis on their legacy and generativity, as well as their degree of independence. People who either gained employment or lost employment placed a greater emphasis on relationships, and people who gained employment placed substantially less emphasis on maintaining roles. People who had a larger comorbidity burden at follow-up tended to indicate that their ability to reduce responsibilities was a much less important consideration in rating their QOL. None of the raw or residualized change scores on the IRT single-domain or -general PROs was associated with any of the catalyst groups, but the Ryff Environmental Mastery raw change score was associated with work change $(p<0.02)$.

Additional file 2: Table S2 shows the results of ANOVA models testing the sensitivity to catalysts of individual items' change scores for each PRO. Although only the Ryff score was associated with a catalyst, itemlevel analyses revealed more sensitivity to catalysts among the PROs. The PROMIS-10 and the Ryff Environmental Mastery subscale had the largest proportion of items associated with catalysts at $23 \%$ and $18 \%$, respectively (using a Type 1 error rate of 0.10 , the probability of exactly this proportion of significant associations is 0.01 and 0.09). In contrast, the NeuroQOL Positive Affect \& Well-Being and Applied Cognition items had relatively few items associated with the catalysts at $8 \%$ and $6 \%$, respectively. Thus the CTT-based and IRT multipledomain measures had more associations than expected, whereas the IRT single-domain measures had less-thanexpected. These findings support the hypothesis that CTT-based and IRT multiple-domain measures are most sensitive to response-shift effects, in contrast with IRT single-domain measures.

Additional file 2: Table S3 shows the alpha coefficients for the baseline, follow-up, and change scores for PROs. The IRT single-domain measures had the highest alpha coefficients for baseline, follow-up, and change scores. The IRT multiple domain and CTT-based measures had slightly lower but still high alpha coefficients at baseline and follow-up, but substantially lower alpha for change scores.

\section{Residual modeling of response shift}

In models predicting residualized change in global physical health, none of the catalysts was associated with longitudinal trajectories (Table 5). Appraisal changes were, however, significant predictors of residualized change in Global Physical Health. Specifically, increased endorsement of Independence appraisal was associated with improved Global Physical Health, after adjusting for positive and negative marital changes. Increased concern about Maintaining Roles was associated with worse Global Physical Health, after adjusting for positive and negative work change. Increased endorsement of Reduce Responsibilities was associated with worse Global Physical Health, after adjusting for increases in comorbidities. Job-status change was unrelated.

In models predicting residualized change in Global Mental Health, positive work change and negative jobstatus change were associated with longitudinal trajectories (Table 5). Positive work change had a trend association with improved Global Mental Health over time. Further, an increased focus on Relationships and a decreased focus on Maintain[ing] Roles were associated with improved global mental health over time. There was a significant interaction effect between the Positive Work Change catalyst and change in Relationship Focused appraisal, suggesting that people who had both positive work changes and an increased focus on 
Table 1 Sample Characteristics and Selection Bias Results

\begin{tabular}{|c|c|c|c|}
\hline Baseline Variable & Attrition Sample $(n=2691)$ & Analytic Sample $(n=1481)$ & t-test $p$-value \\
\hline Continuous Variables: Mean, SD & Mean SD & Mean SD & \\
\hline Age & 48.5313 .32 & 49.8813 .24 & -3.150 .00 \\
\hline Range & 20 93 & $20 \sim 91$ & \\
\hline Total Number of Comorbidities & 3.892 .33 & 3.942 .28 & -0.620 .53 \\
\hline Range & $3.80 \sim 3.98$ & $3.82 \sim 4.06$ & \\
\hline Categorical Variables: N, \% & $\mathrm{N} \%$ & $\mathrm{~N} \%$ & chi2 $p$-value \\
\hline \multicolumn{4}{|l|}{ Respondent Type } \\
\hline Patients & $211178.5 \%$ & $121281.8 \%$ & $14.57 \mathbf{0 . 0 0}$ \\
\hline Caregivers & $52819.6 \%$ & $22715.3 \%$ & \\
\hline Both patient and caregiver & $5219.3 \%$ & $4228.4 \%$ & \\
\hline \multicolumn{4}{|l|}{ Gender } \\
\hline Male & 36213.45 & 20914.11 & 0.350 .84 \\
\hline Female & 232086.21 & 126985.69 & \\
\hline Other & 50.19 & 30.2 & \\
\hline \multicolumn{4}{|l|}{ Co-morbidities } \\
\hline Arthritis & 105739.28 & 63242.67 & $4.52 \mathbf{0 . 0 3}$ \\
\hline Asthma & 49818.51 & 29419.85 & 1.120 .29 \\
\hline Back Pain & 153857.15 & 85557.73 & 0.100 .76 \\
\hline Cancer & 133549.61 & 73049.29 & 0.060 .80 \\
\hline Depression & 136550.72 & 71248.08 & 2.740 .10 \\
\hline Diabetes & 31711.78 & 16811.34 & 0.170 .68 \\
\hline Heart Disease & 2188.10 & 1107.43 & 0.570 .45 \\
\hline High Blood Pressure & 71926.72 & 42928.97 & 2.570 .11 \\
\hline Insomnia & 121044.96 & 65244.02 & 0.450 .50 \\
\hline Kidney Disease & 1435.31 & 805.40 & 0.020 .90 \\
\hline Liver Disease & 1154.27 & 563.78 & 0.590 .44 \\
\hline Lung Disease & 31111.56 & 16611.21 & 0.130 .71 \\
\hline Stroke & 913.38 & 422.84 & 0.900 .34 \\
\hline Ulcer or Stomach Disease & 43916.31 & 20713.98 & 3.880 .05 \\
\hline Other & 111041.25 & 68846.46 & $9.26 \mathbf{0 . 0 0}$ \\
\hline \multicolumn{4}{|l|}{ Marital Status } \\
\hline Single (never married) & 36813.68 & 21114.25 & 1.610 .90 \\
\hline Married & 162760.46 & 89960.7 & \\
\hline Cohabitation /Domestic Partner & 1595.91 & 1006.75 & \\
\hline Divorced & 602.23 & 332.23 & \\
\hline Separated & 33512.45 & 18012.15 & \\
\hline Widowed & 1043.86 & 523.51 & \\
\hline Missing & 381.41 & 60.41 & \\
\hline \multicolumn{4}{|l|}{ Ethnicity } \\
\hline Not Hispanic or Latino & 243990.64 & 137993.11 & 4.870 .03 \\
\hline Hispanic or Latino & 1565.8 & 634.25 & \\
\hline Missing & 963.57 & 392.63 & \\
\hline \multicolumn{4}{|l|}{ Race } \\
\hline American Indian or Alaskan Native & 802.97 & 352.36 & 1.320 .25 \\
\hline
\end{tabular}


Table 1 Sample Characteristics and Selection Bias Results (Continued)

\begin{tabular}{|c|c|c|c|}
\hline Baseline Variable & Attrition Sample $(n=2691)$ & Analytic Sample $(n=1481)$ & t-test $p$-value \\
\hline Middle Eastern & 80.30 & 60.41 & 0.330 .56 \\
\hline South Asian & 70.26 & 40.27 & 0.000 .95 \\
\hline Other Asian & 301.11 & 130.88 & 0.530 .47 \\
\hline Black or African-America & 1425.28 & 593.98 & 3.480 .06 \\
\hline Native Hawaiian, Other Pacific Islander & 160.59 & 70.47 & 0.260 .61 \\
\hline White & 241389.67 & 137292.64 & $10.02 \mathbf{0 . 0 0}$ \\
\hline \multicolumn{4}{|l|}{ Education } \\
\hline Less than High School & 582.16 & 161.08 & \multirow[t]{6}{*}{43.920 .00} \\
\hline Graduated From High School or GED & 71426.53 & 29920.19 & \\
\hline Some College or Technical School & 51919.29 & 25917.49 & \\
\hline Graduated from College & 80329.84 & 48432.68 & \\
\hline Postgraduate School or Degree & 53619.92 & 39026.33 & \\
\hline Missing & 612.27 & 332.23 & \\
\hline \multicolumn{4}{|l|}{ Employment Status at Baseline } \\
\hline Working & 127147.23 & 70547.6 & \multirow[t]{5}{*}{$9.80 \mathbf{0 . 0 2}$} \\
\hline Currently Not working & 36513.56 & 15610.53 & \\
\hline Retired (not due to ill health) & 32312 & 19913.44 & \\
\hline Disabled and/or retired due to health & 67625.12 & 39926.94 & \\
\hline Missing & 562.08 & 221.49 & \\
\hline \multicolumn{4}{|l|}{ Occupational Complexity (O*NET Job Zone) } \\
\hline 1: Little or No Preparation Needed & 1154.27 & 604.05 & \multirow[t]{6}{*}{21.530 .00} \\
\hline 2: Some Preparation Needed & 52919.66 & 25217.02 & \\
\hline 3: Medium Preparation Needed & 87732.59 & 43929.64 & \\
\hline 4: Considerable Preparation Needed & 70426.16 & 44029.71 & \\
\hline 5: Extensive Preparation Needed & 27110.07 & 20313.71 & \\
\hline Missing & 1957.25 & 875.87 & \\
\hline \multicolumn{4}{|l|}{ Income } \\
\hline Less than $\$ 15,000$ & 2479.18 & 1238.31 & \multirow[t]{8}{*}{5.390 .50} \\
\hline$\$ 15,001$ to $\$ 30,000$ & 38714.38 & 20113.57 & \\
\hline$\$ 30,001$ to $\$ 50,000$ & 46117.13 & 25016.88 & \\
\hline$\$ 50,001$ to $\$ 100,000$ & 72727.02 & 43229.17 & \\
\hline$\$ 100,001$ to $\$ 150,000$ & 31911.85 & 18912.76 & \\
\hline$\$ 150,001$ to $\$ 200,000$ & 1013.75 & 704.73 & \\
\hline Over $\$ 200,000$ & 883.27 & 463.11 & \\
\hline Missing & 36113.42 & 17011.48 & \\
\hline \multicolumn{4}{|l|}{ Difficulty Paying Bills ${ }^{b}$} \\
\hline Not at all difficult & NA & 52835.65 & \\
\hline Slightly difficult & NA & 33422.55 & \\
\hline Somewhat difficult & NA & 26417.83 & \\
\hline Very difficult & NA & 1489.99 & \\
\hline Extremely difficult & NA & 1429.59 & \\
\hline Missing & NA & 654.39 & \\
\hline
\end{tabular}

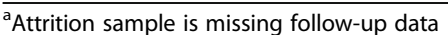

${ }^{b}$ Information available at follow-up only

Bolded numbers reflect statistical signficance (i.e., $p<0.05$ ) 
Table 2 Catalyst Variables Created by Significant Life Event Change over Follow-up

\begin{tabular}{|c|c|c|c|}
\hline Catalyst Domain & $n$ & $\begin{array}{l}\text { Positive: } \\
\text { Negative }\end{array}$ & $\begin{array}{l}\text { Proportion of } \\
\text { Total Sample } \\
\end{array}$ \\
\hline \multicolumn{4}{|l|}{ Marital Status } \\
\hline $\begin{array}{l}\text { Positive Change (single to cohabiting } \\
\text { or married) }\end{array}$ & 74 & 1.51 & 0.08 \\
\hline $\begin{array}{l}\text { Negative Change (single or married } \\
\text { to separated, divorces or widowed) }\end{array}$ & 49 & & \\
\hline \multicolumn{4}{|l|}{ Work Change } \\
\hline $\begin{array}{l}\text { Positive Change (employed to } \\
\text { retired; unemployed to employed } \\
\text { disabled; retired or disabled to } \\
\text { employed) }\end{array}$ & 118 & 2.27 & 0.11 \\
\hline $\begin{array}{l}\text { Negative Change (employed to } \\
\text { unemployed or disabled) }\end{array}$ & 52 & & \\
\hline \multicolumn{4}{|l|}{ Job Status Change } \\
\hline $\begin{array}{l}\text { Positive Change (promotion, i.e., } \\
\text { increase in job complexity) }\end{array}$ & 256 & 0.96 & 0.35 \\
\hline $\begin{array}{l}\text { Negative Change (demotion, i.e., } \\
\text { decrease in job complexity) }\end{array}$ & 266 & & \\
\hline \multicolumn{4}{|l|}{ Comorbidity Burden Change } \\
\hline $\begin{array}{l}\text { Negative Change (Reported new } \\
\text { comorbidities) }\end{array}$ & 44 & NA & 0.03 \\
\hline
\end{tabular}

relationships reported better Global Mental Health over time (Additional file 1: Figure S1). Finally, negative jobstatus change was associated with worsened Global Mental Health, and appraisal change had no impact.

In the models predicting residualized Global Mental Health after adjusting for marital change and comorbidity change, appraisal change was associated with residualized global mental health (Table 5). An increased endorsement of Independence appraisals was associated with better Global Mental Health, after adjusting for positive and negative marital changes; and a decreased endorsement of Reduce Responsibilities appraisals was associated with better Global Mental Health, after adjusting for increases in comorbidities.

In models predicting residualized change in cognitive functioning, no catalysts were associated but appraisal changes were (Table 5). An increased emphasis on Relationships, Maintain[ing] Roles (trend), and Reduc[ing] Responsibilities were associated with improved reported cognitive function over time, after adjusting for the relevant catalyst groups (work and comorbidity change, respectively). Job-status change was unrelated.

In models predicting residualized change in positive affect and well-being, no catalysts were associated but appraisal changes were (Table 5). An increased emphasis on Spiritual Focus and Relationships (trend), and a decreased emphasis on Maintain[ing] Roles and Reduc[ing] Responsibilities were all associated with improved wellbeing over time, after adjusting for the relevant catalyst

Table 3 Change Scores on Patient-Reported Outcomes (post-minus-pre)

\begin{tabular}{|c|c|c|c|c|c|c|}
\hline Measure & Change Score & Obs & Mean & Std. Dev. & Min & $\operatorname{Max}$ \\
\hline \multirow[t]{12}{*}{ QOL Appraisal Profile v2 } & Wellness Focus & 1481 & -0.23 & 2.49 & -9.95 & 8.31 \\
\hline & Health Worries & 1481 & -0.97 & 4.90 & -23.54 & 16.08 \\
\hline & Recent Challenges & 1481 & -0.59 & 4.40 & -18.53 & 15.73 \\
\hline & Spiritual Focus & 1481 & 0.13 & 1.72 & -7.24 & 7.31 \\
\hline & Relationship Focus & 1481 & -0.14 & 2.01 & -10.63 & 9.11 \\
\hline & Maintain Roles & 1481 & 0.02 & 1.19 & -4.27 & 4.11 \\
\hline & Independence & 1481 & 0.07 & 1.42 & -6.45 & 5.91 \\
\hline & Reduce Responsibilities & 1481 & 0.01 & 1.08 & -4.28 & 3.80 \\
\hline & Pursue Dreams & 1481 & 0.09 & 1.47 & -6.09 & 4.95 \\
\hline & Anticipating Decline & 1481 & -0.09 & 1.71 & -8.47 & 6.76 \\
\hline & Worry-Free & 1481 & -0.09 & 1.36 & -5.37 & 5.95 \\
\hline & Lightness of Being & 1481 & -0.08 & 1.28 & -4.96 & 4.65 \\
\hline \multirow[t]{2}{*}{ PROMIS 10} & Global Physical Health Change Score & 1481 & -3.81 & 11.31 & -57.70 & 32.80 \\
\hline & Global Mental Health Change Score & 1481 & -0.40 & 8.03 & -62.50 & 40.50 \\
\hline \multirow[t]{3}{*}{ NeuroQOL } & Applied Cognition Change Score-General concerns & 1464 & -0.27 & 6.14 & -32.40 & 29.00 \\
\hline & Applied Cognition Change Score-Executive function & 1464 & -0.08 & 5.39 & -36.80 & 24.80 \\
\hline & Positive Affect and Well-Being Change Score & 1462 & 0.11 & 5.94 & -41.70 & 31.50 \\
\hline Ryff Psychological Well-Being & Environmental Mastery & 1462 & -0.10 & 12.26 & -50.37 & 54.63 \\
\hline
\end{tabular}




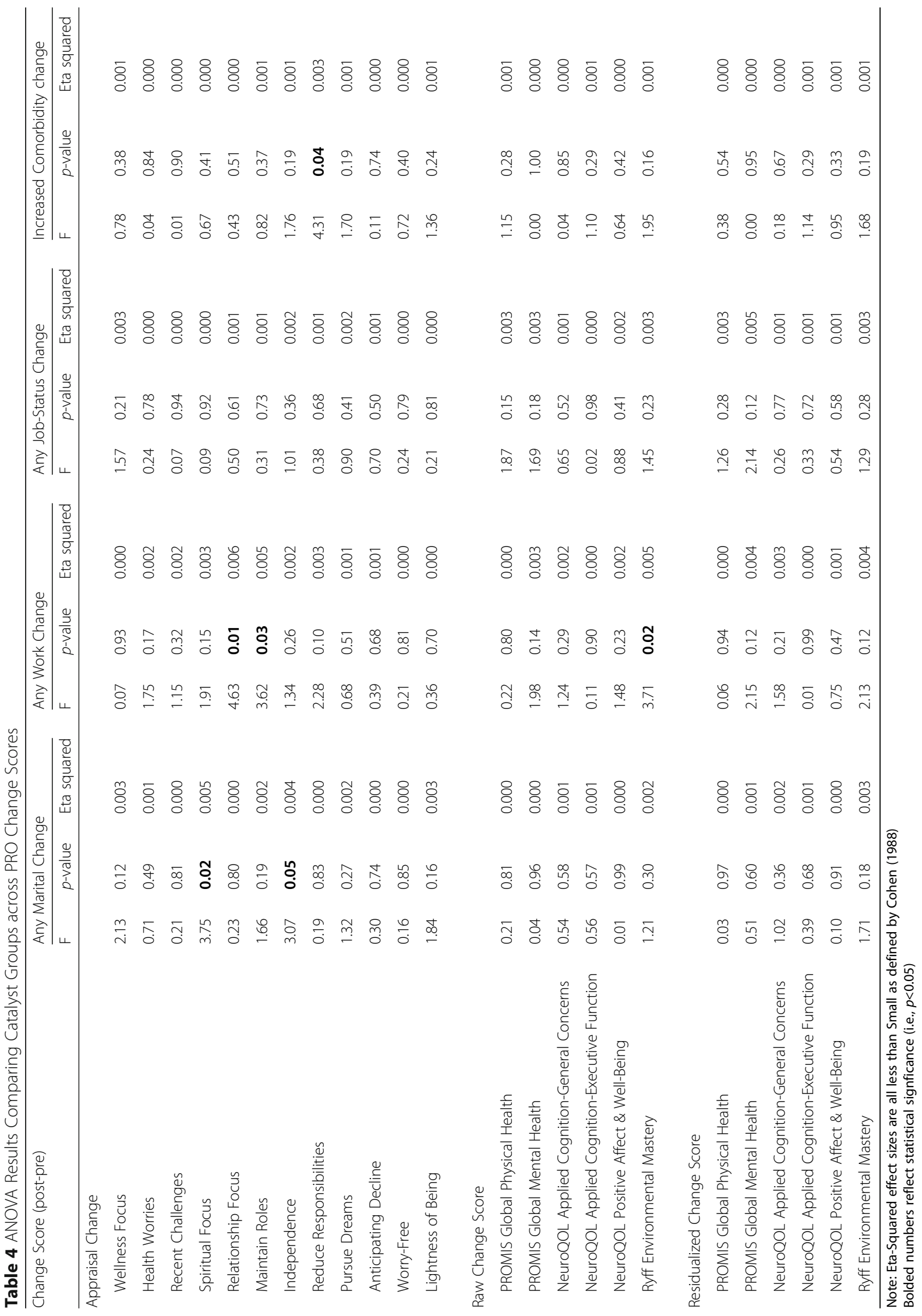


Table 5 Regression Models Examining Catalyst and Appraisal Change Effects on Residualized Outcomes

\begin{tabular}{|c|c|c|c|c|c|c|c|}
\hline Residualized Change Score & & & Coef & Std.Err. & $\bar{t}$ & $P>t$ & Adj. $R^{2}$ \\
\hline \multicolumn{8}{|c|}{ PROMIS Global Physical Health Residualized Change } \\
\hline \multirow[t]{12}{*}{ Main Effects Models } & \multirow[t]{4}{*}{ Marital Change } & Positive Marital Change & -0.02 & 1.42 & -0.02 & 0.99 & \multirow[t]{4}{*}{0.0077} \\
\hline & & Negative Marital Change & -0.20 & 1.70 & -0.12 & 0.91 & \\
\hline & & Spiritual Focus & 0.31 & 0.20 & 1.55 & 0.12 & \\
\hline & & Independence & 0.61 & 0.25 & 2.46 & 0.01 & \\
\hline & \multirow[t]{4}{*}{ Work Change } & Positive Work Change & -0.01 & 1.17 & -0.01 & 0.99 & \multirow[t]{4}{*}{0.0038} \\
\hline & & Negative Work Change & -1.10 & 1.87 & -0.59 & 0.56 & \\
\hline & & Relationship Focus & 0.25 & 0.16 & 1.52 & 0.13 & \\
\hline & & Maintain Roles & -0.72 & 0.28 & -2.63 & 0.01 & \\
\hline & \multirow{2}{*}{ Comorbidity Change } & Comorbidity change & -1.41 & 2.11 & -0.67 & 0.50 & \multirow[t]{2}{*}{0.0016} \\
\hline & & Reduce Responsibilities & -0.56 & 0.30 & -1.85 & 0.07 & \\
\hline & \multirow{2}{*}{ Job-Status Change } & Positive Job-Status Change & -1.04 & 0.85 & -1.23 & 0.22 & \multirow[t]{2}{*}{0.0005} \\
\hline & & Negative Job-Status Change & -1.11 & 0.85 & -1.30 & 0.19 & \\
\hline \multicolumn{8}{|c|}{ PROMIS Global Mental Health Residualized Change } \\
\hline \multirow[t]{4}{*}{ Main Effects Model } & \multirow[t]{4}{*}{ Marital Change } & Positive Marital Change & -0.31 & 0.99 & -0.32 & 0.75 & \multirow[t]{4}{*}{0.0302} \\
\hline & & Negative Marital Change & -0.60 & 1.18 & -0.51 & 0.61 & \\
\hline & & Spiritual Focus & 0.10 & 0.14 & 0.72 & 0.47 & \\
\hline & & Independence & 0.95 & 0.17 & 5.56 & 0.00 & \\
\hline \multirow[t]{7}{*}{ Main Effects Model } & \multirow[t]{7}{*}{ Work Change } & Positive Work Change & 1.53 & 0.81 & 1.88 & 0.06 & \multirow[t]{4}{*}{0.0242} \\
\hline & & Negative Work Change & -0.62 & 1.30 & -0.48 & 0.63 & \\
\hline & & Relationship Focus & 0.43 & 0.11 & 3.77 & 0.00 & \\
\hline & & Maintain Roles & -0.80 & 0.19 & -4.17 & 0.00 & \\
\hline & & Positive Work Change & 1.55 & 0.81 & 1.91 & 0.06 & 0.0248 \\
\hline & & Relationship Focus & 0.43 & 0.11 & 3.75 & 0.00 & \\
\hline & & Maintain Roles & -0.79 & 0.19 & -4.15 & 0.00 & \\
\hline \multirow[t]{8}{*}{ Interaction Model } & & Positive Work Change & 1.48 & 0.81 & 1.82 & 0.07 & 0.0298 \\
\hline & & Relationship Focus & 0.33 & 0.12 & 2.81 & 0.01 & \\
\hline & & Maintain Roles & -0.80 & 0.20 & -3.96 & 0.00 & \\
\hline & & Relationship Focus*Positive Work Change & 1.16 & 0.42 & 2.77 & 0.01 & \\
\hline & & Maintain Roles*Positive Work Change & -0.16 & 0.60 & -0.26 & 0.80 & \\
\hline & & Positive Work Change & 1.52 & 0.82 & 1.86 & 0.06 & 0.0157 \\
\hline & & Relationship Focus & 0.28 & 0.12 & 2.34 & 0.02 & \\
\hline & & Relationship Focus*Positive Work Change & 1.05 & 0.41 & 2.56 & 0.01 & \\
\hline Interaction Model (Final) & & Positive Work Change & 1.48 & 0.81 & 1.83 & 0.07 & 0.0306 \\
\hline & & Relationship Focus & 0.33 & 0.12 & 2.83 & 0.01 & \\
\hline & & Maintain Roles & -0.82 & 0.19 & -4.30 & 0.00 & \\
\hline & & Relationship Focus ${ }^{*}$ ositive Work Change & 1.14 & 0.41 & 2.79 & 0.01 & \\
\hline Main Effects Model & Comorhidity Change & Comorbidity change & -0.07 & 1.47 & -0.05 & 0.96 & 0.0113 \\
\hline & Comorbialty Change & Reduce Responsibilities & -0.81 & 0.21 & -3.87 & 0.00 & \\
\hline Main Effects Model & lak & Positive Job-Status Change & -0.07 & 0.59 & -0.11 & 0.91 & 0.0021 \\
\hline & Job-Status Change & Negative Job-Status Change & -1.23 & 0.60 & -2.06 & 0.04 & \\
\hline NeuroQOL Applied Cognitio & esidualized Change- & ieral Concerns & & & & & \\
\hline Main Effects Models & & Positive Marital Change & 0.64 & 0.80 & 0.80 & 0.43 & -0.0006 \\
\hline & Marital Change & Negative Marital Change & 1.21 & 0.95 & 1.26 & 0.21 & \\
\hline & Miantal Ulanige & Spiritual Focus & 0.01 & 0.11 & 0.07 & 0.94 & \\
\hline & & Independence & -0.16 & 0.14 & -1.09 & 0.28 & \\
\hline & & Positive Work Change & -0.21 & 0.66 & -0.31 & 0.76 & 0.0005 \\
\hline & Work Change & Negative Work Change & -1.78 & 1.04 & -1.71 & 0.09 & \\
\hline & Vvork Change & Relationship Focus & 0.05 & 0.09 & 0.49 & 0.63 & \\
\hline & & Maintain Roles & 0.16 & 0.16 & 1.00 & 0.32 & \\
\hline & Comorhidity Changa & Comorbidity change & 0.66 & 1.16 & 0.57 & 0.57 & 0.0246 \\
\hline & Comorbialty Change & Reduce Responsibilities & 0.91 & 0.17 & 5.50 & 0.00 & \\
\hline & Joh_Status Change & Positive Job-Status Change & 0.43 & 0.47 & 0.91 & 0.36 & -0.0010 \\
\hline & Job-Status Change & Negative Job-Status Change & 0.06 & 0.48 & 0.13 & 0.90 & \\
\hline
\end{tabular}


Table 5 Regression Models Examining Catalyst and Appraisal Change Effects on Residualized Outcomes (Continued)

\begin{tabular}{|c|c|c|c|c|c|c|c|}
\hline \multicolumn{8}{|c|}{ NeuroQOL Applied Cognition Residualized Change-Executive Function } \\
\hline \multirow[t]{12}{*}{ Main Effects Models } & & Positive Marital Change & 0.60 & 0.70 & 0.86 & 0.39 & -0.0013 \\
\hline & \multirow{3}{*}{ Marital Change } & Negative Marital Change & -0.04 & 0.83 & -0.05 & 0.96 & \\
\hline & & Spiritual Focus & -0.01 & 0.10 & -0.06 & 0.96 & \\
\hline & & Independence & -0.15 & 0.12 & -1.21 & 0.23 & \\
\hline & \multirow{4}{*}{ Work Change } & Positive Work Change & 0.04 & 0.57 & 0.06 & 0.95 & 0.0044 \\
\hline & & Negative Work Change & 0.09 & 0.90 & 0.10 & 0.92 & \\
\hline & & Relationship Focus & -0.05 & 0.08 & -0.66 & 0.51 & \\
\hline & & Maintain Roles & 0.40 & 0.13 & 2.98 & 0.00 & \\
\hline & \multirow{2}{*}{ Comorbidity Change } & Comorbidity change & 1.17 & 1.02 & 1.15 & 0.25 & 0.0068 \\
\hline & & Reduce Responsibilities & 0.43 & 0.15 & 2.93 & 0.00 & \\
\hline & \multirow{2}{*}{ Job-Status Change } & Positive Job-Status Change & 0.46 & 0.41 & 1.13 & 0.26 & -0.0006 \\
\hline & & Negative Job-Status Change & 0.22 & 0.42 & 0.54 & 0.59 & \\
\hline \multicolumn{8}{|c|}{ NeuroQOL Positive Affect \& Well-Being Residualized Change } \\
\hline \multirow[t]{12}{*}{ Main Effects Models } & \multirow{4}{*}{ Marital Change } & Positive Marital Change & -0.22 & 0.79 & -0.27 & 0.79 & 0.0002 \\
\hline & & Negative Marital Change & 0.14 & 0.94 & 0.15 & 0.88 & \\
\hline & & Spiritual Focus & 0.22 & 0.11 & 2.00 & 0.05 & \\
\hline & & Independence & 0.22 & 0.14 & 1.54 & 0.12 & \\
\hline & \multirow{4}{*}{ Work Change } & Positive Work Change & 0.69 & 0.65 & 1.06 & 0.29 & 0.0104 \\
\hline & & Negative Work Change & -0.63 & 1.02 & -0.61 & 0.54 & \\
\hline & & Relationship Focus & 0.17 & 0.09 & 1.82 & 0.07 & \\
\hline & & Maintain Roles & -0.54 & 0.15 & -3.55 & 0.00 & \\
\hline & \multirow{2}{*}{ Comorbidity Change } & Comorbidity change & -1.24 & 1.15 & -1.07 & 0.28 & 0.0107 \\
\hline & & Reduce Responsibilities & -0.60 & 0.17 & -3.63 & 0.00 & \\
\hline & \multirow{2}{*}{ Job-Status Change } & Positive Job-Status Change & -0.17 & 0.47 & -0.37 & 0.71 & -0.0009 \\
\hline & & Negative Job-Status Change & -0.46 & 0.47 & -0.98 & 0.33 & \\
\hline \multicolumn{8}{|c|}{ Ryff Environmental Mastery } \\
\hline \multirow[t]{8}{*}{ Main Effects Models } & \multirow{4}{*}{ Marital Change } & Positive Marital Change & -1.41 & 1.60 & -0.88 & 0.38 & 0.0094 \\
\hline & & Negative Marital Change & 2.58 & 1.90 & 1.36 & 0.18 & \\
\hline & & Spiritual Focus & 0.40 & 0.23 & 1.76 & 0.08 & \\
\hline & & Independence & 0.61 & 0.29 & 2.12 & 0.03 & \\
\hline & \multirow{4}{*}{ Work Change } & Positive Work Change & 2.58 & 1.31 & 1.97 & 0.05 & 0.0181 \\
\hline & & Negative Work Change & -0.86 & 2.07 & -0.42 & 0.68 & \\
\hline & & Relationship Focus & 0.28 & 0.19 & 1.51 & 0.13 & \\
\hline & & Maintain Roles & -1.37 & 0.31 & -4.43 & 0.00 & \\
\hline \multirow[t]{9}{*}{ Interaction model: } & \multirow{5}{*}{ Work Change } & Positive Work Change & 2.59 & 1.31 & 1.98 & 0.05 & 0.0174 \\
\hline & & Negative Work Change & -0.89 & 2.07 & -0.43 & 0.67 & \\
\hline & & Relationship Focus & 0.28 & 0.19 & 1.50 & 0.13 & \\
\hline & & Maintain Roles & -1.43 & 0.33 & -4.34 & 0.00 & \\
\hline & & Maintain Roles* Positive Work Change & 0.49 & 0.94 & 0.52 & 0.60 & \\
\hline & \multirow{2}{*}{ Comorbidity Change } & Comorbidity change & -3.44 & 2.32 & -1.48 & 0.14 & 0.0339 \\
\hline & & Reduce Responsibilities & -2.09 & 0.33 & -6.31 & 0.00 & \\
\hline & \multirow{2}{*}{ Job-Status Change } & Positive Job-Status Change & -1.04 & 0.95 & -1.09 & 0.28 & -0.0002 \\
\hline & & Negative Job-Status Change & -0.97 & 0.96 & -1.00 & 0.32 & \\
\hline
\end{tabular}

Note: Bolded $R^{2}$ cells indicate small Effect Sizes as defined by Cohen (1988).

groups (marital, work, and comorbidity change, respectively). Job-status change was unrelated.

In models predicting residualized change in Environmental Mastery, an increased Spiritual Focus and Independence, and a decreased focus on Maintain[ing] Roles and Reduc[ing] Responsibilities were associated with improved Environmental Mastery. Positive work change and change in Maintaining-Roles appraisal were associated with improved Environmental Mastery (Table 5), supporting a direct response-shift effect.

Figure 3 summarizes the effect sizes across the univariable and multivariable models, contrasting the three types of measures. Although effects were generally small, they were systematically smaller for the IRT Single-Domain Measures (ANOVA $\mathrm{F}=8.35, \mathrm{df}=2,242, p<0.001$, etasquared $=0.065$ ). The IRT Multiple-Domain and CTT-
Based measures were more likely to achieve effect sizes that met or exceed Cohen's [43] criteria for small effects.

\section{Discussion}

Our findings suggest that PROs developed in different ways and/or with different goals may be differentially sensitive to response-shift effects. The IRT singledomain measures evaluated in this study were not impacted by major life events at the item- or scale-level. In contrast, the IRT multiple domain and CTT-based measures were more sensitive to such catalysts. For the IRT multiple-domain measure, response shift was evidenced only at the item level, whereas the CTT-based measure demonstrated this sensitivity at both the item- and scale-level. 

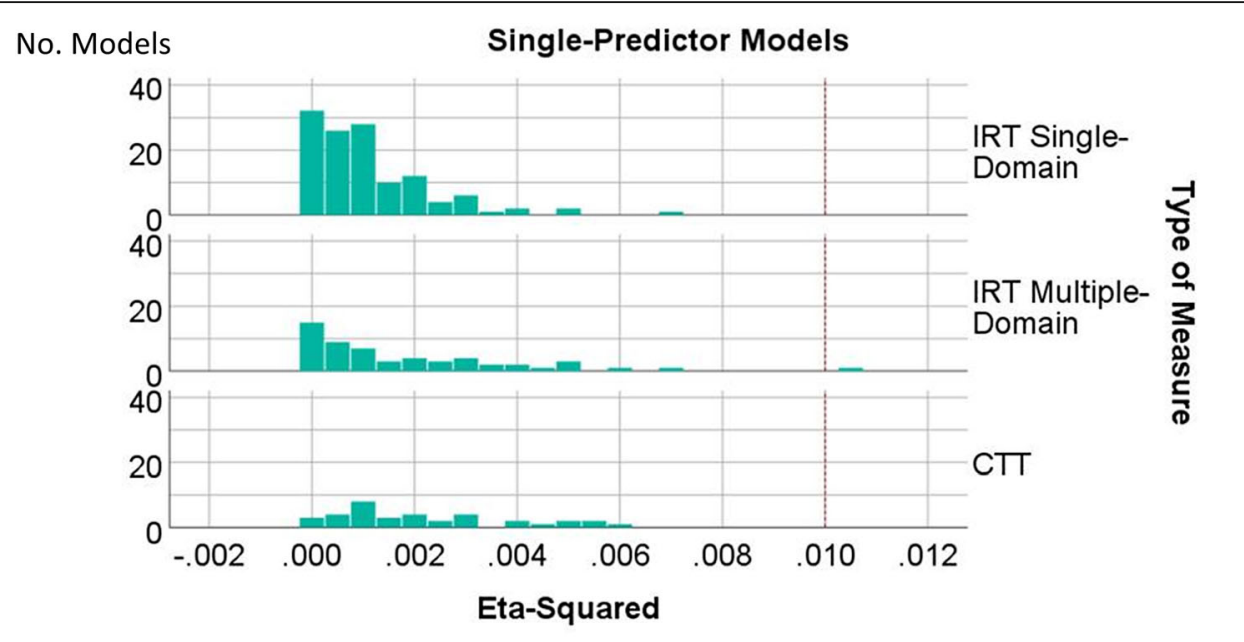

No. Models

Multiple-Predictor Models
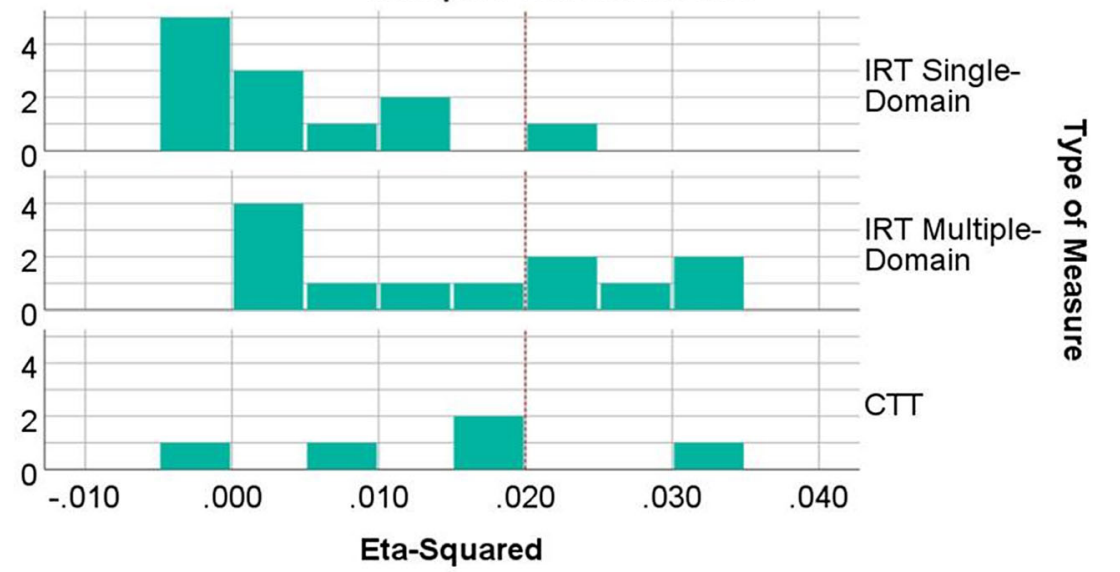

Fig. 3 Distribution of effect sizes by type of measure for single-predictor models (top panel) and multiple-predictor models (bottom panel). Effects were generally small, and were systematically smaller for the IRT Single-Domain Measures. The IRT Multiple-Domain and CTT-Based measures were more likely to achieve effect size that met or exceeded Cohen's [43] criteria for small effects. Dashed vertical line indicates cutpoint of eta-squared $\geq 0.01$ for single-predictor models, and $\geq 0.02$ for multiple predictor models

Our findings suggest that response-shift effects are present and detectable using a direct measure of changes in appraisal. The catalyst variables were associated with different appraisal process trajectories. These associations had face validity, i.e., they made sense. Marital change was associated with an increased focus on legacy or generativity and independence, whereas work change was associated with an increased focus on relationships and a decreased focus on role maintenance. Increased comorbidity burden was associated with a decreased emphasis on reducing responsibilities.

The IRT single-domain measures evaluated in this study seemed to change in the same way over time (i.e., in lock-step). In contrast, the IRT-general and CTT measures' items changed in much less of a lockstep fashion. Thus, compared to IRT single-domain measures, IRT multiple domain and CTT-based measures could be more sensitive to response-shift effects over time. They have lower stability over time because different appraisal processes apparently influence subscale items differentially.

The implications of the study findings are that appraisal processes - and response shift effects - are relevant and influence the interpretation of change even for IRT single-domain measures. The IRT multiple domain global health measure and the CTT-based Ryff subscale were sensitive to life events and to appraisal processes.

Despite the present study's notable strengths (i.e., large heterogeneous sample, longitudinal data), its limitations must be acknowledged. First, several factors prevent us from making definitive statements about how IRT/CTT measures are differentially responsive to catalyst and response-shift effects. The findings were generally small effect sizes, some of which may reflect weak operationalization of catalysts. We cannot know the true valence of the catalysts from the perspective of the respondent 
(e.g., divorce can be a positive change for some, retirement can be a challenging transition for others). Small samples of exemplar measures also limit our ability to generalize. The results could be due to peculiarities of the scales used, not necessarily the methods used to create them. Further, although IRT-developed measures might generally emphasize unidimensionality and are stricter and more rigorous than CTT-developed measures, this generalization that may not always apply. For example, the PROMIS and NeuroQOL item banks reportedly balanced items that were "unidimensional enough" with items deemed clinically important. Finally, other sources of measurement error could be at play. For example, the small sample size of change groups limited our statistical power to detect response-shift effects. Therefore, the evidence should be considered preliminary, and future research should attempt to replicate the study with a larger sample of IRT- and CTT-based measures, explicit measurement of the valence of catalysts, and larger sample sizes within catalyst and no-catalyst groups.

In summary, our findings highlight several underappreciated notions about QOL measurement. Even when item difficulty and scale unidimensionality are constant, the construct to which they refer may change subjective meaning. Differences in appraisal are related to all of the types of measures regardless of their provenance, and are not a form of bias. It might be tempting to consider creating scales that are not subject to response shift due to changes in appraisal. This would, however, neither be feasible nor useful. The only way to reduce differences in the implicit meaning and context that individuals read into items would be to add detailed instructions to constrain their ways of thinking. This would not only be cumbersome; it would distort our understanding of individuals' actual experience. Direct assessment of changes in the cognitive criteria that people use to evaluate their QOL is far more fruitful. How individuals appraise $\mathrm{QOL}$ is as interesting and important as the numerical rating of QOL that they provide.

\section{Conclusions}

Our findings suggest that response-shift effects are present and detectable using a direct measure of changes in appraisal. PROs developed in different ways and/or with different goals may be differentially sensitive to responseshift effects. The IRT single-domain measures evaluated in this study were not impacted by major life events at the item- or scale-level. In contrast, the IRT multiple domain and CTT-based measures were more sensitive to such catalysts. For the IRT multiple-domain measure, response shift was evidenced only at the item level, whereas the CTT-based measure demonstrated this sensitivity at both the item- and scale-level. The implications of the study findings are that appraisal processes - and response shift effects - are relevant and influence the interpretation of change even for IRT single-domain measures. This study is the first to address this research question, so its findings are preliminary and suggestive and should be replicated in studies with more measures of each type.

\section{Supplementary information}

Supplementary information accompanies this paper at https://doi.org/10. 1186/s41687-019-0162-x.

Additional file 1: Figure S1. Moderated response-shift effect. This figure illustrates the significant interaction effect between Positive Work Change and Relationship Focus in predicting residualized change in global mental health. Thus, people who had both positive work changes and an increased relationship focus tended to have notably better global mental health over time, after adjusting for changes in their focus on maintaining roles.

Additional file 2: Table S1. Description of QOLAPV2 Component Scores. Table S2. ANOVA Results Comparing Catalyst Groups for PRO Change Items. Table S3. Alpha Reliability Coefficients for PROs at Baseline, Follow-up and Change scores.

\section{Abbreviations}

ANOVA: Analysis of variance; CTT: Classical test theory; DIF: Differential item functioning; HIPAA: Health Insurance Portability and Accountability Act; IRT: Item Response Theory; PRO: Patient-reported outcome; PROMIS: PatientReported Outcome Measurement Information System; QOL: Quality-of-life

\section{Acknowledgements}

We are grateful to the patients who participated in this study, to Jie Zhang, M.P.H., for statistical programming support, and to Roland B. Stark, M.Ed., for helpful input on the manuscript and tables.

\section{Authors' contributions}

CES designed the research study. WM provided access to the sample. CES performed the research. CES, BDS, and BDR analyzed the data. CES wrote the paper and WM, BDS, and BDR edited the manuscript. All authors read and approved the final manuscript.

\section{Funding}

This work was not funded by any external agency.

Availability of data and materials

The study data are confidential and thus not able to be shared.

\section{Ethics approval and consent to participate}

The study was reviewed and approved by the New England Review Board (NEIRB\#15-254), and all participants provided informed consent. All procedures performed in studies involving human participants were in accordance with the ethical standards of the institutional and/or national research committee and with the 1964 Helsinki declaration and its later amendments or comparable ethical standards.

Consent for publication

No individual person's data is included in the present work.

\section{Competing interests}

All authors declare that they have no potential conflicts of interest and report no disclosures.

\section{Author details}

${ }^{1}$ DeltaQuest Foundation, Inc., 31 Mitchell Road, Concord, MA 01742, USA ${ }^{2}$ Departments of Medicine and Orthopaedic Surgery, Tufts University Medical School, Boston, MA, USA. ${ }^{3}$ Los Alamos National Laboratory, Los Alamos, NM, USA. ${ }^{4}$ Rare Patient Voice, LLC, Towson, MD, USA. ${ }^{5}$ Department of Epidemiology and Population Health, Division of Community Collaboration \& Implementation Science, Albert Einstein College of Medicine, Bronx, NY, USA. 
Received: 29 May 2019 Accepted: 21 November 2019

\section{Published online: 23 January 2020}

\section{References}

1. Bernhard, J., Hurny, C., Maibach, R., Herrmann, R., \& Laffer, U. (1999). Quality of life as subjective experience: Reframing of perception in patients with colon cancer undergoing radical resection with or without adjuvant chemotherapy. Swiss Group for Clinical Cancer Research (SAKK). Annals of Oncology, 10(7), 775-782.

2. Finkelstein, J. A., Razmjou, H., \& Schwartz, C. E. (2009). Response shift and outcome assessment in orthopedic surgery: Is there is a difference between complete vs. partial treatment? Journal of Clinical Epidemiology, 82, 1189-1190.

3. Joore, M. A., Potjewijd, J., Timmerman, A. A., \& Anteunis, L. J. (2002). Response shift in the measurement of quality of life in hearing impaired adults after hearing aid fitting. Quality of Life Research, 11(4), 299-307.

4. Ring, L., Hofer, S., Heuston, F., Harris, D., \& O'Boyle, C. A. (2005). Response shift masks the treatment impact on patient reported outcomes: The example of individual quality of life in edentulous patients. Health and Quality of Life Outcomes, 3, 55.

5. Rohs, F. R., Langone, C. A., \& Coleman, R. K. (2001). Response shift bias: A problem in evaluating nutrition training using self-report measures. Journal of Nutrition Education, 33(3), 165-172.

6. Schwartz, C. E., Feinberg, R. G., Jilinskaia, E., \& Applegate, J. C. (1999). An evaluation of a psychosocial intervention for survivors of childhood cancer: Paradoxical effects of response shift over time. Psychooncology, 8(4), 344-354.

7. Schwartz, C. E., Wheeler, H. B., Hammes, B., Basque, N., Edmunds, J., Reed, G., Ma, Y., Li, L., Tabloski, P., \& Yanko, J. (2002). Early intervention in planning end-of-life care with ambulatory geriatric patients: Results of a pilot trial. Archives of Internal Medicine, 162(14), 1611-1618.

8. Sprangers, M. A. G. (1996). Response-shift bias: A challenge to the assessment of patients' quality of life in cancer clinical trials. Cancer Treatment Reviews, 22(Suppl. A), 55-62.

9. Schwartz, C. E., Stucky, B. D., Rivers, C. S., Noonan, V. K., \& Finkelstein, J. A (2018). Quality of life and adaptation in people with spinal cord injury: Response shift effects five-years post-injury. Archives of Physical Medicine and Rehabilitation, 99, 1599-1608.

10. Ahmed, S., Mayo, N. E., Wood-Dauphinee, S., Hanley, J. A., \& Cohen, S. R. (2004). Response shift influenced estimates of change in health-related quality of life poststroke. Journal of Clinical Epidemiology, 57(6), 561-570.

11. Chin, K., Fukuhara, S., Takahashi, K., Sumi, K., Nakamura, T., Matsumoto, H., et al. (2004). Response shift in perception of sleepiness in obstructive sleep apnea-hypopnea syndrome before and after treatment with nasal CPAP. Sleep, 27(3), 490-493.

12. Postulart, D., \& Adang, E. M. (2000). Response shift and adaptation in chronically ill patients. Medical Decision Making, 20(2), 186-193.

13. Visser, M. R., Smets, E. M., Sprangers, M. A., \& de Haes, H. J. (2000). How response shift may affect the measurement of change in fatigue. Journal of Pain and SymptomManagement, 20(1), 12-18.

14. Westerman, M., Hak, T., Groen, H., \& van der Wal, G. (2003). Using SEIQOLDW for measuring response shift in quality of life in palliative treatment of small cell lung cancer patients. Quality of Life Research, 12(7), 45.

15. Wilson, I. B. (1999). Clinical understanding and clinical implications of response shift. Social Science \& Medicine, 48(11), 1577-1588.

16. Bach, J. R., \& Tilton, M. C. (1994). Life satisfaction and well-being measures in ventilator assisted individuals with traumatic tetraplegia. Archives of physical medicine and rehabilitation, 75(6), 626-632.

17. Sprangers, M. A. G., \& Schwartz, C. E. (1999). Integrating response shift into health-related quality of life research: A theoretical model. Social Science \& Medicine, 48(11), 1507-1515.

18. Rapkin, B. D., \& Schwartz, C. E. (2004). Toward a theoretical model of qualityof-life appraisal: Implications of findings from studies of response shift. Health and Quality of Life Outcomes, 2(1), 14.

19. Rapkin, B. D., Garcia, I., Michael, W., Zhang, J., \& Schwartz, C. E. (2016). Distinguishing appraisal and personality influences on quality of life in chronic illness: Introducing the quality-of-life appraisal profile version 2. Quality of Life Research, 26, 2815-2829.

20. Rapkin, B. D., Garcia, I., Michael, W., Zhang, J., \& Schwartz, C. E. (2018). Development of a practical outcome measure to account for individual differences in quality-of-life appraisal: The brief appraisal inventory. Quality of Life Research, 27, 423-436. https://doi.org/10. 1007/s11136-017-1722-2.
21. Rapkin, B. D., \& Schwartz, C. E. (2016). Distilling the essence of appraisal: A mixed methods study of people with multiple sclerosis. Quality of Life Research, 25(4), 793-805.

22. Schwartz, C. E., Powell, V. E., \& Rapkin, B. D. (2017). When global rating of change contradicts observed change: Examining appraisal processes underlying paradoxical responses over time. Quality of Life Research, 26, 847-857. https://doi.org/10.1007/s11136-016-1414-3.

23. Schwartz, C. E., Quaranto, B. R., Rapkin, B. D., Healy, B. C., Vollmer, T., \& Sprangers, M. A. G. (2014). Fluctuations in appraisal over time in the context of stable and non-stable health. Quality of Life Research, 23(1), 9-19. https://doi.org/10.1007/s11136-013-0471-0.

24. Schwartz, C. E., \& Rapkin, B. D. (2015). Appraisal assessment in patientreported outcome research: Methods for uncovering the personal context and meaning of quality of life. Quality of Life Research, 24, 13-14.

25. Schwartz, C. E., Snook, E., Quaranto, B., Benedict, R. H., Rapkin, B. D., \& Vollmer, T. (2013). Cognitive reserve and appraisal in multiple sclerosis Multiple Sclerosis and Related Disorders, 2(1), 36-44. https://doi.org/10.1016/j. msard.2012.07.006

26. Morganstern, B. A., Bernard, B., Dalbagni, G., Shabsigh, A., \& Rapkin, B. D. (2011). The psychological context of quality of life: A psychometric analysis of a novel idiographic measure of bladder cancer patients' personal goals and concerns prior to surgery. Health and Quality of Life Outcomes, 9(10). https://doi.org/10.1186/1477-7525-9-10.

27. Oort, F. J. (2005). Using structural equation modeling to detect response shifts and true change. Quality of Life Research, 14, 587-598.

28. Oort, F. J., Visser, M. R. M., \& Sprangers, M. A. G. (2005). An application of structural equation modeling to detect response shifts and true change in quality of life data from cancer patients undergoing invasive surgery. Quality of Life Research, 14, 599-609.

29. Embretson, S. E., \& Reise, S. P. (2000). Item response theory for psychologists. London: Lawrence Erlbaum Associates.

30. Li, Y., \& Rapkin, B. D. (2009). Classification and regression tree analysis to identify complex cognitive paths underlying quality of life response shifts: A study of individuals living with HIV/AIDS. Journal of Clinical Epidemiology, 62, 1138-1147.

31. Schwartz, C. E., \& Rapkin, B. D. (2004). Reconsidering the psychometrics of quality of life assessment in light of response shift and appraisal. Health and Quality of Life Outcomes, 2, 16.

32. Schwartz, C. E., Michael, W., Zhang, J., Rapkin, B. D., \& Sprangers, M. A. G. (2018). Assessing reserve-building pursuits and person characteristics: Psychometric validation of the DeltaQuest reserve-building measure. Quality of Life Research, 27, 423-436. https://doi.org/10.1007/s11136-017-1694-2.

33. National Institute of Neurological Disorders and Stroke User Manual for the Quality of Life in Neurological Disorders (Neuro-QOL) Measures, version 2.0, March 2015

34. Hays, R. D., Bjorner, J. B., Revicki, D. A., Spritzer, K. L., \& Cella, D. (2009). Development of physical and mental health summary scores from the patient-reported outcomes measurement information system (PROMIS) global items. Quality of Life Research, 18, 873-880. https://doi.org/10.1007/ s11136-009-9496-9.

35. Ryff, C. D. (1989). Happiness is everything, or is it? Explorations on the meaning of psychological well-being. Journal of Personality and Social Psychology, 57, 1069-1081.

36. Ryff, C. D. (1989). Scales of psychological well-being scoring protocol. University of Wisconsin Institute on aging. Wl: Madison.

37. Hanmer, J., \& Cherepanov, D. (2016). A single question about a respondent's perceived financial ability to pay monthly bills explains more variance in health utility scores than absolute income and assets questions. Quality of Life Research, 25(9), 2233-2237.

38. Sangha, O., Stucki, G., Liang, M. H., Fossel, A. H., \& Katz, J. N. (2003). The selfadministered comorbidity questionnaire: A new method to assess comorbidity for clinical and health services research. Arthritis Care \& Research, 49(2), 156-163.

39. Tsacoumis, S., \& Willison, S. (2010). O*NET analyst occupational skill ratings: Procedures. Raleigh, NC: National Center for O*NET development.

40. Schwartz, C. E., Michael, W., \& Rapkin, B. D. (2017). Resilience to health challenges is related to different ways of thinking: Mediators of physical and emotional quality of life in a heterogeneous rare-disease cohort. Quality of Life Research, 26(11), 3075-3088.

41. Reed, B. R., Mungas, D., Farias, S. T., Harvey, D., Beckett, L., Widaman, K. Hinton, L., \& DeCarli, C. (2010). Measuring cognitive reserve based on the decomposition of episodic memory variance. Brain, 133(Pt 8), 2196-2209. https://doi.org/10.1093/brain/awq154. 
42. Cohen, J. (1992). A power primer. Psychological Bulletin, 112, 155-159.

43. Cohen, J. (1988). Statistical power analysis for the behavioral sciences Lawrence Erlbaum associates, Hillsdale, NJ.

44. StataCorp. (2017). Stata statistical software: Release 15. College Station, TX: StataCorp LLC.

\section{Publisher's Note}

Springer Nature remains neutral with regard to jurisdictional claims in published maps and institutional affiliations.

Submit your manuscript to a SpringerOpen ${ }^{\mathcal{O}}$ journal and benefit from:

- Convenient online submission

- Rigorous peer review

- Open access: articles freely available online

- High visibility within the field

- Retaining the copyright to your article

Submit your next manuscript at $\boldsymbol{\wedge}$ springeropen.com 